\title{
A relação entre federalismo e municipalização: desafios para a construção do sistema nacional e articulado de educação no Brasil
}

Gilda Cardoso de Araujo

Universidade Federal do Espírito Santo

\section{Resumo}

Este artigo é oriundo de pesquisa teórica, de natureza histórica e conceitual, que analisa a configuração das instituições políticas municipais e federativas, a forma de assimilação dessas instituições políticas no Brasil e como se articularam à organização da educação nacional. Discute a organização do ensino, no que se refere à oferta de instrução elementar, em sua relação com as instituições políticas federativas e municipais, indicando a construção puramente ideológica - e também idealista - do discurso municipalista brasileiro desde a década de 1940, que foi retomado com vigor por ocasião do debate constituinte da década de 1980. Nesse debate, foi completamente desconsiderada toda uma tradição de pensamento político sobre a organização do Estado e da educação brasileiros, analisada neste artigo para mostrar que o debate considerado pioneiro sobre a municipalização do ensino, entre Anísio Teixeira e Carlos Correa Mascaro, omitia essa tradição como se a organização do ensino em bases municipais estivesse descolada do debate sobre a organização do Estado brasileiro, omissão essa que marcará também o debate sobre a temática da década de 1980 até os nossos dias. As conclusões indicam a urgente necessidade de formulação de políticas educacionais que permitam constituir um sistema verdadeiramente nacional e articulado de educação, considerando os aspectos históricos e políticos específicos que o federalismo e o municipalismo assumiram no Brasil.

\section{Palavras-chave}

Federalismo - Municipalização - Organização do ensino. 


\section{The relation between federalism and municipalization: challenges for the construction of an articulated national education system in Brazil}

Gilda Cardoso de Araujo

Universidade Federal do Espírito Santo

\begin{abstract}
This article results from a theoretical study of a historical and conceptual nature that analyzes the configuration of municipal and federative political institutions, the form of their assimilation in Brazil, and how they are articulated to the organization of national education. It discusses the organization of teaching, insofar as it relates to the offer of elementary instruction, and its relation to municipal and federative political institutions, pointing out the purely ideological - and also idealistic - construction of the municipalist discourse in Brazil since the 1940s, which reappeared vigorously during the constitutional debate of the 1980s. In such debate a whole tradition of political thinking on the organization of the Brazilian State and education was brushed aside. This tradition is discussed here to show that the debate between Anisio Teixeira and Carlos Correa Mascaro, regarded as pioneering on the municipalization of teaching, ignored this tradition as if the organization of teaching were disconnected from the debate about the organization of the Brazilian State, an omission that is felt throughout the debate on this issue from the 1980s to this day. The conclusions drawn here point to the urgent need to reformulate educational policies, allowing the construction of a truly articulated national education system, considering the particular historical and political aspects assumed by federalism and municipalism in Brazil.
\end{abstract}

\section{Keywords}

Federalism - Municipalization - Organization of teaching.
Contact:

Gilda Cardoso de Araujo

Rua Aristides Navarro 45, apto 302

29016-040 - Vitória - ES

E-mail: gilda.vix@terra.com.br 
0 fenômeno de municipalização das matrículas na etapa elementar de escolarização é recente, com uma aceleração notável a partir da segunda metade da década de 1990. Em menos de cinco anos (a partir da implantação do Fundo de Manutenção e Desenvolvimento do Ensino Fundamental e de Valorização do Magistério - FUNDEF), a tendência estadualista da oferta de instrução elementar, com mais de um século de vigência, foi invertida.

Evidentemente essa inversão tem estreita relação com a descentralização propugnada pelo movimento Reforma do Estado brasileiro. Os organismos multilaterais de financiamento indicavam, na década 1990, o ajuste fiscal duradouro, as reformas econômicas orientadas para o mercado e a inovação dos instrumentos de política social como mecanismos relevantes para garantir e ampliar a governança do Estado nacional. A descentralização das políticas sociais no Brasil, como muitos trabalhos indicam (Gentili, 1994; Peroni, 2003; Rosar, 1995; Tiramonti, 1997, entre outros), integra-se nesse quadro de novos padrões de regulação estatal.

Todavia, essa explicação não é suficiente para o debate sobre a descentralização do ensino no Brasil nas últimas décadas, que se traduziu na municipalização. Não é suficiente, exatamente por desconsiderar toda a história de (con)formação do Estado brasileiro e da organização da educação e por desconsiderar que uma engenharia institucional complexa como a descentralização de perfil municipalista não pode ser explicada apenas a partir dos determinantes mais atuais da globalização.

\section{A municipalização do ensino}

As propostas de municipalização do ensino remontam à década de 1920, com a atuação da Associação Brasileira de Educação (ABE), e foram sistematizadas por Anísio Teixeira nas décadas seguintes e refutadas por Carlos Correa Mascaro entre os anos de 1950 e 1960.

A questão restringiu-se a considerar a municipalização do ensino como algo especí- fico da área, portanto, não dialogou com uma longa tradição de pensamento político que articulava o debate sobre a organização do Estado brasileiro com o debate sobre a organização da educação nacional. Também desprezou uma análise da formação de nossas instituições políticas municipais e federativas, como se essas fossem a-históricas e não construídas social e politicamente.

A retomada do debate sobre a municipalização do ensino na década de 1980 também incorreu no mesmo reducionismo, com a configuração de três tendências marcantes de análise ${ }^{1}$ que não se articularam com a questão da organização do Estado e muito menos dialogaram com a tradição do pensamento político brasileiro. Disso resultou, como enfatizam estudiosos do tema, a predominância de abordagens ou muito ideologizadas ou muito concretas, faltando estudos que tivessem um enfoque mais teórico e conceitual.

\section{Federalismo e poder local}

Foi nessa ausência que nos pautamos para a definição do título desse artigo: federalismo e municipalização do ensino. 0 pressuposto foi tornar a organização do Estado brasileiro e suas instituições municipais e federativas um problema de política educacional, no que tange, especificamente, à oferta da etapa elementar de escolarização, que constitui direito do cidadão à educação. Esse pressuposto tem um significado ainda maior se considerarmos que a descentralização do ensino na década de 1990 ocorreu de forma vinculada a uma organização federativa

1. Categorizadas por nós a partir de três abordagens: 1) participacionista, ou seja, artigos, dissertações e teses que defendiam a associação do poder local com o poder popular ou da descentralização com a democracia; entre os representantes dessa tendência podemos citar Gadotti (1989; 1993), Romão (1990; 1992), Bordignon (1989; 1993), Jacobi (1990); 2) pragmática, com trabalhos definindo a descentralização que enfatizasse delegação, recursos e resultados; entre as autoras que mais traduziram essa tendência podem ser citadas Mello (1986;1990), Maia (1989; 1990, 1995), Barreto (1990; 1992; 1995); e 3) político-ideológica, com argumentos que denunciavam a exploração política sobre o tema da municipalização do ensino e da falta de consistência doutrinária das propostas, representada pelos trabalhos de Cunha (1991), Azanha (1995) e Arelaro (1980; 1989). 
de perfil tridimensional, com o município sendo definido como terceiro ente federado, caso único entre as federações existentes.

Definimos o federalismo como um pacto pelo qual várias unidades territoriais se obrigam mutuamente de forma voluntária. Todavia, o modelo de federalismo erigido nos Estados Unidos não surgiu para reforçar a democracia e o poder local. Ao contrário, foi concebido a partir da necessidade de diminuir o poder local, o igualitarismo político e a democracia direta, com o fortalecimento do poder central e do sistema representativo.

0 período pós-independência caracterizou-se pela ameaça de anarquia e de tirania tanto pela ausência de um poder central, quanto pela ausência de garantias legais contra os interesses parciais de qualquer grupo político que ocupasse as funções públicas estaduais. Esse risco entre um desfecho anárquico ou tirânico era decorrência das disputas entre as maiorias devedoras e as minorias credoras a partir do fim da Guerra de Independência, quando os comerciantes britânicos começaram a negar novos créditos aos comerciantes norte-americanos que não haviam quitado dívidas anteriores. Estes, por sua vez, começaram a pressionar seus devedores, os pequenos proprietários rurais, que passaram a se sentir frustrados em seus objetivos de progresso econômico, ainda mais por terem contribuído, muitas vezes, com seus próprios bens para a Guerra de Independência. Os comerciantes norte-americanos pressionavam os pequenos proprietários para que pagassem suas dividas, mediante apelações judiciais que impunham prisão aos que não quitavam seus débitos.

Conflitos decorrentes desse contexto tiveram grande ressonância na política dos estados, visto que os pequenos proprietários endividados passaram a pressionar os legislativos estaduais e estes começaram a aprovar medidas para aliviar a situação dos devedores, principalmente pela autorização de emissão de papel moeda (Gargarella, 2002).

A questão sobre o alcance do Poder Legislativo local e a relação entre representan- tes e representados configurou-se como um dos principais temas do debate político. Isso porque esses conflitos ocorreram no contexto pósindependência, cujo emblema era a liberdade diante dos poderes, favorecendo a ampliação da politização e da participação mais direta do homem comum na vida pública, o que, por sua vez, expressou um igualitarismo político em que 70 a 90\% dos homens adultos podiam votar ou serem votados (Kramnick, 1993). Esse foi o contexto mais geral que deflagrou, na década de 1780 , os debates em torno da necessidade não de uma simples revisão, mas de uma reformulação completa do texto constitucional. Assim, entre 1787 e 1789, os representantes dos 13 estados norte-americanos iniciaram a discussão sobre a definição de poderes que reforçassem o poder central, sem, contudo, enfraquecer o poder dos estados. Estava então sendo erigido o Federalismo nos moldes que conhecemos modernamente.

Em decorrência desse contexto, uma primeira conclusão importante que chegamos cotejando com a leitura dos "Artigos federalistas" é que a associação que normalmente é feita entre os conceitos de federalismo, de descentralização e de democratização carece de sustentação histórica e conceitual (Hamilton; Jay; Madison, 1993).

Tocqueville (2001), com sua análise da igualdade e da democracia na América, e Proudhon (2001), com sua defesa de um sistema federal total, viam o modelo de federação erigido nos Estados Unidos como um artifício. 0 primeiro, pelo fato de o federalismo desconsiderar a pujança do poder local; o segundo, por associar o federalismo com o centralismo, visto que teria atribuído poderes demasiados à União.

0 modelo de federalismo original não prescreveu a educação como uma das tarefas do poder central ou do poder local. Atribuímos isso a dois fatores: o primeiro, é que a ênfase dos federalistas não era o igualitarismo político nem o poder local, porquanto a finalidade era garantir certa centralização governamental propícia à segurança e à ordem. 0 segundo fator estaria ligado à análise dos costumes 
norte-americanos, que atribuíam grande valor à educação como instrumento de formação religiosa e moral para a vida em sociedade.

Da análise sobre a relação entre federalismo, poder local e educação com base nos clássicos, destacamos que Proudhon (2001) foi o único autor que acentuava a educação como um dos serviços públicos que não deveria prescindir de um papel mais ativo do poder central. Embora expressasse que só uma federação universal seria capaz de organizar de forma igualitária a oferta de escolaridade média, argumentava que o poder central seria fundamental para a fundação, a criação e a instalação de escolas, segundo as demandas das comunas.

\section{Instituições políticas: federalismo e municipalismo}

No Brasil, a descentralização desde muito cedo foi assumindo contornos federalistas e depois municipalistas. Adotou-se como ideia corrente a fórmula que identifica o federalismo com maior democracia e maior descentralização e, no geral, referimo-nos a esses aspectos como componentes essenciais de qualquer federação. Constatamos que essa fórmula precisa ser bastante relativizada, na medida em que, como tributária da ideia de contrato social, a ideia de federação (ou o contrato federativo) pode estar vinculada a uma lógica de perfil bastante centralizador e até mesmo antidemocrático.

Quanto ao município, desde a sua origem, em Roma, nunca esteve associado aos princípios de autonomia local, uma vez que surgiu como estratégia do Estado romano para coordenar a ação política nos territórios conquistados, depois serviu de instrumento relevante para a configuração do Estado absolutista português e, por fim, como mecanismo do reino português para colonização das terras brasileiras, no que diz respeito ao controle da aristocracia colonial e da arrecadação de tributos e rendas. Nesse sentido, ao contrário das comunas europeias, que consolidaram pactos com o poder central para fazer frente às prer- rogativas da nobreza, os municipios foram configurados apenas como braço político da estratégia de centralização do poder (D’Aquino, 1940; Herculano, 1916; Zenha, 1962; Faoro, 2000; Leal, 1993).

Em decorrência dessa associação entre 0 município e os interesses centralizadores, a configuração das instituições federativas no Brasil não considerou o municipalismo, uma vez que as ideias federalistas surgiram como contraposição à excessiva centralização monárquica. Não havia sequer, nas demandas federalistas, os clamores republicanos, visto que o liberalismo brasileiro, antes mesmo de propugnar as liberdades civis, tomou para si a bandeira da descentralização como forma de adaptação política às novas necessidades econômicas advindas do fim do tráfico de escravos e da mudança do eixo econômico do Nordeste para o Sudeste (Carvalho, 1993; 1998; Torres, 1967).

Se nos Estados Unidos o federalismo surgiu como alternativa às tendências centrífugas das 13 Colônias, no Brasil, surgiu como alternativa à centralização política e administrativa do período colonial e imperial. 0 mote era pôr fim ao poder central nas eleições locais e acomodar as elites regionais nos postos de comando. Assim, se na própria ideia original de federação não encontramos sustentação teórica para associá-la à descentralização e à democratização do poder político, tampouco poderemos encontrar essa associação no Brasil, porquanto fora o regionalismo a base para a defesa da organização federativa. Por isso, nos primeiros tempos de implantação do federalismo, após a Proclamação da República, a descentralização caracterizou-se pela feição estadualista, com a restrição significativa da autonomia municipal, embora o município se tenha integrado de forma subordinada como peça importante na engrenagem da Política dos Governadores (Torres, 1967; Abrucio, 1998; Nunes, 1920).

A crise na Bolsa de Nova York, de 1929, provocou efeitos na economia cafeeira e, consequentemente, trouxe instabilidade política para as oligarquias rurais, atingindo o pacto 
oligárquico que sustentava a federação erigida em 1891. A Revolução Constitucionalista de 1932 assinalou o último dos conflitos em torno da federação, que ficou, por muito tempo, secundarizada ou mesmo esquecida como se houvesse um consenso em torno de sua pertinência.

Foi justamente num momento em que o intervencionismo estatal se expressou como tendência no cenário político e institucional que o municipalismo se configurou como uma nova expressão das demandas por autonomia local. Todavia, somente em meados da década de 1940, com o processo de abertura política após o Estado Novo, é que o municipalismo ganhou contornos mais nítidos, como movimento reivindicatório que conseguiu assegurar, na Carta de 1946, dispositivos que previam a repartição de rendas e de competências para os municípios.

Esses dispositivos foram resultados da pressão exercida pela campanha municipalista liderada por Rafael Xavier, em que encontramos argumentos altamente reveladores da natureza ideológica e idealista desse movimento. $\mathrm{Na}$ verdade, a análise da campanha municipalista no Brasil, em qualquer época, revela que os únicos que lutaram pelos municípios e defenderam a autonomia municipal foram os municipalistas (Xavier, 1948; Nunes, 1957). Não foram liberais, positivistas, separatistas nem autoritários, simplesmente municipalistas. Dessa forma, a federação tridimensional que começou a configurar-se a partir dessa campanha não foi obra política de nenhuma tradição de pensamento político isoladamente.

Antes da campanha de Rafael Xavier, não havia um movimento orgânico em prol das franquias municipais, mas somente vozes isoladas, como a do jurista, escritor e historiador João de Azevedo Carneiro Maia, considerado por alguns como "O Pai do Municipalismo Brasileiro", em virtude de uma monografia que escreveu em 1878 e que foi publicada em 1883, intitulada $O$ município: estudos sobre administração local. Nesta, o autor abordava a história das 'comunas' na Europa e propunha um sistema de organização municipal para que se repensassem as nos- sas antigas estruturas coloniais. A monografia foi reeditada por seu neto, Mario Maia Coutinho, em 1962 - sendo prefaciada por Corifeu de Azevedo Marques -, provavelmente para contestar a aprovação do projeto de lei do Deputado Federal Medeiros Netto, do ano de 1951, propondo considerar Tavares Bastos "Patrono" dos municípios brasileiros. Essa aprovação foi, inclusive, aplaudida e apoiada pelo próprio Rafael Xavier, na época presidente da Associação Brasileira dos Municípios - ABM.

Da campanha liderada por Rafael Xavier, foi fundada a ABM, cujas bases de defesa do municipalismo eram marcadas por incoerências. A primeira foi a evocação constante do pensamento nacionalista e autoritário de Alberto Torres como fundamento teórico e político da campanha. A segunda incoerência diz respeito ao completo desconhecimento da situação de tutela das vilas no período colonial, visto que a campanha afirmava a defesa de um retorno às origens dos nossos primeiros núcleos coloniais, para destacar a autonomia local como um dos componentes intrínsecos da nossa formação cultural, social e política. A terceira incoerência foi apontar o modelo dual de federação caracterizado pela União e pelos estados como uma inversão do regime federativo que originalmente e em todas as federações existentes se caracterizava pela dupla e não pela tripla soberania.

A campanha municipalista, com a consequente fundação da ABM, apesar de originada de grandes equívocos históricos e conceituais, sobrepujou o debate sobre o federalismo como forma de organização nacional. 0 federalismo, a partir da promulgação da Constituição Federal de 1946, não só deixou de ser tema de reflexão mesmo considerando as estruturais desigualdades entre estados e regiões - como foi ampliado, com uma interpretação de autonomia municipal tão alargada que conferia ao município "status" de membros da federação.

No período de redemocratização do país, após o Regime Militar, a campanha municipalista foi retomada com a atuação do Instituto Brasileiro de Administração Municipal (IBAM), tribu- 
tário do movimento da década de 1940. Essa retomada também foi perpassada por um viés ideológico e idealista ao inserir formalmente, na Constituição Federal de 1988, o município como ente federado. Essa inserção não levou em consideração os impactos políticos nem os impactos financeiros e acirrou ainda mais os conflitos federativos ao adotar os mecanismos de competências comuns num contexto histórico marcado por um federalismo altamente predatório.

Todavia, a inscrição do município como ente federado e a constituição dos sistemas municipais de ensino no Texto Constitucional de 1988 - em que pese o engajamento de muitos educadores na retomada da temática da municipalização do ensino - não foram defendidas pelas entidades da área de educação que se fizeram presentes no debate constituinte. Ao contrário, essas entidades foram bastante cautelosas quanto às teses municipalistas na organização do ensino brasileiro. Foi a atuação do IBAM, na "Subcomissão de municípios e regiões", que consolidou a inscrição de uma federação tridimensional no Texto Constitucional de 1988, representando o ponto de convergência entre o municipalismo e o federalismo, como instituições políticas, e a organização da educação brasileira, convergência tecida por equívocos conceituais e históricos que reduziram a democracia à descentralização municipalista (Brasil, 1987a; 1987b; 1987c).

Além de desconsiderar as questões técnicas de repartição de rendas e de competências e a questão sociopolítica das profundas desigualdades entre regiões, estados e municípios (Souza, 2001), o debate constituinte desprezou toda uma tradição de pensamento político brasileiro com sólida reflexão sobre a relação entre município, federação e educação, que resgatamos, em parte, neste artigo, a fim de problematizar a atual organização do Estado e da educação nacional.

\section{Federalismo e municipalização do ensino: ideias políticas}

Tavares Bastos (1975) pode ser considerado um dos primeiros formuladores da ideia de federação no Brasil. Considerava que a essência das reformas liberais no país era a garantia da autonomia das províncias e propunha como modelo de organização nacional uma monarquia federativa com educação política que reforçasse as "virtudes cívicas".

Assim, o alicerce de sua defesa de uma descentralização federativa era a província e não o município. Quanto à organização da educação no país, sua proposta consistia na criação de uma taxa escolar que não confrontasse com o princípio da gratuidade do ensino, sendo que a província teria papel preponderante na disseminação da instrução elementar com a colaboração do Governo Central para as pequenas províncias (com menor capacidade orçamentária).

Assim como Tavares Bastos, Rui Barbosa (1946) foi outro personagem emblemático no debate da configuração histórica das ideias de federalismo e educação no país. Os Pareceres de 1882 destacavam a necessidade de uma organização nacional do ensino, pois uma reforma radical do ensino público seria a primeira de todas as necessidades da pátria. Também traziam a proposta do estabelecimento de um fundo escolar mediante a cobrança de taxa, tal qual o modelo de Tavares Bastos. Esse fundo escolar não deveria ser uma instituição provincial, tal qual defendia Tavares Bastos, mas sim nacional, e o Governo Central deveria colaborar com governos locais com a criação de novos aportes financeiros.

Contudo, a posição de Rui Barbosa (1947) quanto ao necessário equilíbrio entre um projeto nacional de educação e a autonomia local foi negligenciada no processo de implantação da federação brasileira, processo do qual foi um dos protagonistas. Ainda observa-se uma grande contradição no pensamento de Rui Barbosa quanto à oferta de instrução elementar no período entre os pareceres e a Proclamação da República, pois no projeto constitucional de sua lavra, a educação não era colocada como um projeto nacional, como constava nos Pareceres de 1882.

No entanto, fica evidente que Rui Barbosa defendia, como Tavares Bastos, a preponde- 
rância das províncias sobre as municipalidades no seu projeto de federação. E como político e intelectual engajado ao liberalismo de seu tempo, também acentuava a precedência da federação sobre o conjunto de todas as medidas da reforma liberal.

Não é recente o mito da superioridade paulista em relação às demais províncias/estados da federação. A imagem de uma locomotiva puxando 20 vagões, presente durante os embates da Revolução Constitucionalista de 1932, foi construída muito antes, ao final do Império, com o movimento separatista liderado por João Alberto Sales (1983). Em sua obra "A pátria paulista”, defendia o regime republicano nos moldes norte-americanos, assegurando "liberdades" aos proprietários rurais paulistas. Para ele, o Separatismo seria um elemento de "progresso" político que deveria preceder a federação. Além disso, seria um poderoso mecanismo para garantir a autonomia do ensino na província de São Paulo.

Júlio de Castilhos (2003) ganhou notoriedade na província do Rio Grande do Sul mediante o exercício do jornalismo político. Desde a sua passagem pela Faculdade de Direito de São Paulo, onde escreveu para os periódicos estudantis “A Evolução" e "A República”, vinha aprimorando as suas qualidades de jornalista político que incitava polêmicas. Entretanto, foi como editor de "A Federação", órgão do Partido Republicano Rio-Grandense, a partir de 1884, que ficou conhecido pela sua pregação do positivismo comteano, sua crítica ácida à monarquia e à defesa intransigente da abolição da escravatura.

Assim, a Monocracia comteana foi a base do "castilhismo" (forma de governo republicana e ditatorial). Castilhos participou do processo constituinte de 1890 , defendendo interpretação radical do federalismo e, no Rio Grande do Sul, redigiu praticamente sozinho um projeto constitucional de feições marcadamente monocráticas. No Rio Grande do Sul, pode-se afirmar que o castilhismo significou a submissão dos municípios gaúchos e também valori- zação do ensino, pois colocou a educação pública no topo das despesas do estado.

Alberto Torres (1982), escritor e político que representa o pensamento autoritário brasileiro, integrou o grupo dos críticos da Constituição de 1891. Para ele, a federação teria se transformado em estadualismo. Nesse sentido, propunha uma organização do Estado cujos elementos fossem o nacionalismo e as corporações. Denunciava a desorganização das instituições em decorrência da implantação de modelos estranhos à nossa realidade, pois as autonomias estaduais e municipais seriam os "nervos mais sensíveis da nossa política". Assim, defendia a necessidade de reforço dos poderes federais, visto que a ênfase nos poderes estaduais representava ampliação dos antagonismos e dos conflitos. Em sua proposta de projeto constitucional, o poder central deveria intervir nos estados para garantir educação.

Antônio Paim (1987), ao comentar a vida e a obra de Oliveira Vianna, destaca que, na Primeira República, o país teve um arcabouço constitucional que diferia flagrantemente da atuação dos governantes e que, nesse contexto, várias formas de autoritarismo foram elaboradas, sendo a primeira delas o castilhismo de inspiração comteana que desprezava solenemente o liberalismo. Para Paim (1987), foi exatamente a elite castilhista-borgista que chegou ao poder com o Movimento de 1930 e o Estado Varguista.

Contudo, outras doutrinas autoritárias estiveram presentes no cenário político brasileiro como a de Jackson Figueiredo, que fundamentaria o integralismo; a de Francisco Campos; e a de Azevedo de Amaral, entre outros. Oliveira Vianna foi colaborador de Vargas², mas segundo Paim (1987), sua teoria tinha algo a ver com o autoritarismo, mas não se reduzia a isso.

Oliveira Vianna $(1938 ; 1987 ; 2002)$ teria, mais do que defendido outra teoria autoritária, desenhado uma proposta inteiramente original ao destacar que a modernização do país deveria abranger o plano das instituições políticas, como pretendiam os liberais desde a

2. Depois da Revolução de 30 , tornou-se Consultor da Justiça do Trabalho. 
independência, mas essa modernização só poderia ser levada a termo pelo Estado, o que Wanderley Guilherme dos Santos (1998) chamou de "autoritarismo instrumental", ou seja, a ideia de que o autoritarismo seria um instrumento transitório para ser utilizado num país com grande diferenciação política, social, territorial, cultural e econômica, a fim de se chegar à implementação de instituições liberais autênticas. Assim, só o Estado teria condições de romper com as tradições dos clãs e instituir, de fato, um liberalismo político.

Para Vianna (1987), os verdadeiros construtores da nacionalidade procuravam mecanismos de reforço do poder central, enquanto os liberais lutavam pelo municipalismo, pelo federalismo, pela democracia como sinônimos do progresso político, o que seria um equívoco visto que a organização municipal foi anterior à organização social e por ato de delegação do poder central. Daí, segundo ele, o idealismo e a inadequação da instituição municipal no Brasil. 0 autor designa esse fenômeno como "marginalismo das elites políticas", principalmente no que se refere às ideias homogêneas calcadas no modelo norte-americano de Tavares Bastos e Rui Barbosa.

0 mal do federalismo não estaria na descentralização, mas sim na sua uniformidade. Os defensores do federalismo no Brasil não levavam em consideração o despreparo para a autonomia local das antigas províncias e acabaram uniformizando aquilo que pretendiam diversificar. Exemplificando essa crítica, cita Oliveira Vianna (1938) que se alguém se dispusesse a procurar a originalidade de tipos de governo local nas vinte constituições estaduais, promulgadas após 1891, deparar-se-ia com absoluta semelhança entre elas, com a única exceção do Rio Grande do Sul, embora as realidades sociais, econômicas, políticas e culturais de cada estado da federação fossem muito distintas: "0 estudo dos textos das suas Constituições, na sua abstração verbal, é de secundária importância para o historiador, como para o sociólogo" (p. 328).

Assim, coerentemente com sua defesa de um Estado unitário e desconcentrado, Oliveira Vianna $(1938 ; 1987 ; 2002)$ defende o dirigismo estatal em matéria educacional, não se limitando aos primeiros anos de escolarização e atingindo até o ensino superior, visto que nesse nível era formada a elite dirigente do país e era realizada a alta cultura nacional.

Do IV Congresso Nacional dos Municípios, organizado pela ABM no bojo da campanha municipalista, em 1957, participou também Anísio Teixeira que, representando oficialmente o Ministério da Educação e Cultura, elaborou e relatou a tese oficial da $A B M$, intitulada “Municipalização do ensino primário". Nesse documento, podemos vislumbrar algumas ideias que se tornaram caras aos defensores da municipalização nas décadas seguintes. Percebemos também que, a partir desse momento, o debate sobre a organização da educação nacional foi deslocado do campo mais amplo dos intelectuais e políticos - que não eram educadores - para o campo mais específico dos profissionais da educação. A tese da municipalização do ensino no contexto da federação brasileira assumiu, com esses últimos, contornos mais nítidos.

Anísio Teixeira evoca, na famosa tese (Nunes, 1957), o princípio constitucional da gratuidade e da obrigatoriedade do ensino primário, destacando que a Carta de 1946 distribuiu as competências relativas à oferta da etapa elementar entre os municípios, os estados e a União, estendendo-se a todo o território nacional nos estritos limites das deficiências locais.

Anísio Teixeira (1956) identifica descentralização, federação e democracia como dimensões indissociáveis de uma política educacional que considerasse a unidade na diversidade. Com esses argumentos, ele parece intencionar colocar uma pedra sobre as questões relativas à federação, ao poder local e à articulação de ambos ao tema da organização da educação nacional, visto que sumariamente associa federação à democracia, desqualificando, portanto, os opositores da descentralização ao tachá-los de antidemocráticos.

Essa posição de Anísio Teixeira pode guardar relação com a sua oposição à política 
educacional centralizadora desenvolvida a partir de 1930, pois defendia que o governo central deveria definir apenas as normas gerais da educação. Os currículos, os métodos, as práticas didáticas e tudo o que dizia respeito à ordem política e didático-pedagógica deveriam ficar no campo da autonomia profissional dos professores. De toda forma, a maneira taxativa como situa o problema da descentralização está eivada de idealismo ou de "marginalismo intelectual”, ao desconsiderar, segundo o debate dos autores que ele chama de "unitaristas", as condições objetivas dos municípios e os aspectos histórico-culturais do povo brasileiro.

Ao que parece, Teixeira (1956) tinha consciência do potencial de iniquidade de sua proposta, mas a possibilidade de ampliação do sistema sobrepujava a questão da igualdade de condições de oferta:

Com efeito, as escolas passariam a ser locais e, desse modo, a ser mantidas em condições desiguais, segundo os recursos dos municípios, mas, por isso mesmo, a serem mais numerosas, pois umas custariam menos que as outras. (p. 174)

Enquanto Anísio Teixeira pode ser considerado um idealista no que se refere ao seu modelo de organização nacional pautado nas tradições clássicas do liberalismo de Tavares Bastos e de Rui Barbosa, o professor da Universidade de São Paulo, Carlos Correa Mascaro, pode ser considerado um realista ou um objetivista no que se refere à questão da municipalização do ensino.

Pouco depois da divulgação da tese sobre a municipalização do ensino de Anísio Teixeira no IV Congresso das Municipalidades, Carlos Correa Mascaro publicou, no ano de 1960, o livro “0 município de São Paulo e o ensino primário”, originalmente uma monografia para o concurso de livre-docência na cadeira de "Administração Escolar e Educação Comparada" da Faculdade de Filosofia, Ciências e Letras da Universidade de São Paulo.
Nessa obra, o autor começa enunciando que o municipalismo estaria ganhando um número cada vez maior de adeptos entre aqueles que viam na descentralização uma das chaves para a solução de vários problemas ligados ao subdesenvolvimento do país e também entre aqueles que invariavelmente adotavam novidades para não serem acusados de anacronismo. Para o autor, a municipalização, mais do que transferência ou ampliação de atribuições administrativas, significava responsabilidades relativas ao financiamento da obra a ser realizada. Esse seria para ele o nó górdio do debate sobre a municipalização do ensino. Mascaro (1960) indica que o desinteresse dos poderes locais pelo ensino talvez decorresse da escassez de recursos financeiros, uma vez que os municípios brasileiros sempre foram os menos dotados de rendas públicas, mas também sugere que o desinteresse pela expansão do ensino teria causas ligadas aos interesses dos chefes políticos locais de não perderem "braços" no trato da lavoura.

Carlos Correa Mascaro, com esse estudo, contrapunha-se ao fôlego que as teses municipalistas ganhavam na década de 1940, situando a questão nos marcos histórico-culturais da formação social brasileira e na realidade da administração pública da capital paulista. Foi justamente a partir da polarização entre seus argumentos e os de Anísio Teixeira que o debate sobre a municipalização do ensino ressurgiu na década de 1980. No entanto, esse debate não mais considerava a questão federativa como inerente às propostas em disputa. Nada do que formou essa longa tradição de debate político sobre a organização nacional foi retomado, restando apenas os argumentos circunscritos às especificidades educacionais e ligado ao participacionismo, ao pragmatismo ou mesmo à denúncia do mandonismo local como impedimento para a municipalização, mas sem o resguardo do que a teoria política nacional havia formulado sobre o tema. Nessa ambiência é que a descentralização de perfil municipalista foi inscrita na Constituição Federal de 1988, e sobre os equívocos dessa inscrição, apontados 
a partir dessa trajetória institucional e das ideias políticas discutidas neste trabalho, é que recairão as nossas conclusões.

\section{Conclusões}

Podemos afirmar que a tradição de pensamento liberal no Brasil não foi municipalista, apesar de considerar relevante a organização municipal nos moldes equivocadamente comunais. A descentralização federativa defendida por Tavares Bastos e Rui Barbosa era provincial, visto que se baseava na federação dual dos Estados Unidos.

Outra questão relevante é que a tradição de pensamento liberal não foi essencialmente republicana. Foi federalista antes de qualquer coisa, associando descentralização com autonomia provincial e não municipal, em decorrência, talvez, da estreita relação, no Brasil, entre o municipalismo e o centralismo.

0 “não republicanismo" com federalismo da tradição liberal brasileira foi algo que perdurou na nossa trajetória institucional, haja vista que, por ocasião da reforma constitucional, tivemos um plebiscito sobre a forma de governo (República ou Monarquia Constitucional) e o sistema de governo (Parlamentarismo ou Presidencialismo), mas não sobre o regime federativo, considerado cláusula pétrea no Texto Constitucional.

lsso, apesar de o federalismo ter assumido o significado de regionalismos que, no passado, foram intensificados pelas teorias e pelos movimentos separatistas e que hoje permanecem, de certa forma, no jogo político-institucional, sob a forma predatória de relação entre os entes federados brasileiros, com reflexos, inclusive, na organização da educação nacional, que não assegura quantitativa e qualitativamente recursos, infraestrutura e insumos de forma equânime para todos os brasileiros.

Nesse quadro, parece-nos que a tradição de pensamento nacionalista (classificada de autoritária, com certa razão) deu uma contribuição importante ao debate sobre a organização do Estado e do ensino, contribuição que talvez tenha sido desprezada pelos equívocos e preconceitos relacionados às ideias de federação, município, descentralização e democratização.

Dessa forma, chegamos aos dias atuais com a urgente necessidade de formulação de políticas educacionais que permitam constituir um sistema verdadeiramente nacional e articulado de educação, medida que o Governo Federal está adotando a partir desse ano com a realização de conferências municipais e estaduais de educação, culminando, no ano de 2010, com a Conferência Nacional de Educação (CONAE). Entretanto, os debates e as proposições das conferências municipais, estaduais e nacional serão inócuos se não levarem em consideração a necessidade de desnaturalizar a federação como sinônimo de democracia - principalmente a federação tridimensional erigida pela Constituição Federal de 1988 -, bem como se não realizarem uma análise criteriosa do caráter predatório dos entes federados, que incide diretamente na prestação dos serviços públicos e, mais especificamente, na garantia e efetividade do direito à educação da população brasileira. 


\section{Referências bibliográficas}

ABRUCIO, F. L. Os barões da federação: os governadores e a redemocratização brasileira. São Paulo: HUCITEC, 1998.

ARELARO, L. R. G. A descentralização na Lei 5.692/71: coerência ou contradição? 1980. 204 f. Dissertação (Mestrado em Educação)- Faculdade de Educação, Universidade de São Paulo, São Paulo, 1980.

A municipalização do ensino e o poder local. ANDE, São Paulo, v. 8, n. 14, p. 22-26, 1989.

AZANHA, J. M. P. Uma ideia sobre a municipalização do ensino. In: . Educação: temas polêmicos. São Paulo: Martins Fontes, 1995. p. 105-115.

BARBOSA, R. Obras completas: reforma do ensino primário e várias instituições complementares da instrução pública. Rio de Janeiro: Ministério da Educação e Saúde, v. 10, 1946. (Tomos 1-4).

Obras completas: queda do império. Rio de Janeiro: Ministério da Educação e Saúde, v. 16, 1947. (Tomo 3).

BARRETO, E. S. de S. A universalização do ensino fundamental e o papel dos municípios - contribuição à sua redefinição. ANDE, São Paulo, v. 9, n. 16, p. 20-25, 1990.

Onde se quer chegar com a municipalização do ensino fundamental? Cadernos de Pesquisa, São Paulo, n. 80, p. 5155, fev. 1992.

Descentralizar e redistribuir nos sistemas de ensino. Cadernos de Pesquisa, São Paulo, n. 95, p. 73-78, nov. 1995.

BASTOS, A. C. T. A província: estudo sobre a descentralização no Brasil. 3. ed. São Paulo: Nacional, 1975.

BORDIGNON, G. A escola cidadã: uma utopia municipalista. Educação Municipal, São Paulo, v. 2, n. 4, p. 5, 1989.

Gestão democrática do sistema municipal de educação. In: GADOTTI, M.; ROMÃO, J. E. (Orgs.). Município e educação. São Paulo: Cortez, 1993. p. 135.

BRASIL. Assembléia Nacional Constituinte. Comissão de Organização do Estado. Subcomissão da União, Distrito Federal e Territórios. Relatório e anteprojeto. Brasilia, 1987a. 33 f.

. Assembléia Nacional Constituinte. Comissão da Família, da Educação, Cultura e Esportes, da Ciência e Tecnologia e da Comunicação. Subcomissão da Educação, Cultura e Esportes. Relatório. 1987c. 49 f.

. Assembléia Nacional Constituinte. Comissão de Organização do Estado. Subcomissão de Municípios e Regiões. Relatório. Brasilia, 1987b. 43 f.

CARVALHO, J. M. de. Federalismo y centralización en el imperio brasileño: historia y argumento. In: CARMAGNANI, M. (Coord.).

Federalismos latinoamericanos: México, Brasil, Argentina. México: Fondo de Cultura Económica, 1993. p. 51-80.

Pontos e bordados: escritos de história e política. Belo Horizonte: UFMG, 1998.

CASTILHOS, J. de. 0 pensamento político de Júlio de Castilhos. Porto Alegre: Martins Livreiro, 2003.

CUNHA, L. A. Educação, estado e democracia no Brasil. São Paulo: Cortez, 1991.

D’AQUINO, I. 0 município: sua conceituação histórica e jurídico-constitucional. Florianópolis: [s.n.], 1940.

FAORO, R. Os donos do poder: formação do patronato político brasileiro. 10. ed. São Paulo: Globo, 2000. 2 v. (Grandes nomes do pensamento brasileiro).

GADOTTI, M. Educação municipal e poder popular. Educação Municipal, São Paulo, v. 2, n. 4, p. 60, 1989.

Sistema municipal de educação. In: GADOTTI, M.; ROMÃO, J. E. (Orgs.). Município e educação. São Paulo: Cortez, 1993. p. 71. 
GARGARELLA, R. En nombre de la constitución: el legado federalista dos siglos después. In: BORÓN, A. (Org.). La filosofía política moderna: de Hobbes a Marx. Buenos Aires: CLACSO, 2002. CD-ROM.

GENTILI, P. Neoliberalismo, qualidade total e educação. Petrópolis: Vozes, 1994.

HAMILTON, A.; JAY, J.; MADISON, J. Os artigos federalistas. Rio de Janeiro: Nova Fronteira, 1993.

HERCULANO, A. História de Portugal: desde o começo da monarchia até o fim do reinado de Afonso III. 7. ed. Rio de Janeiro: Francisco Alves, 1916. (Tomos 6-8).

IGLÉSIAS, F. Apresentação. In: TORRES, A. A organização nacional. Primeira parte: a Constituição. 4. ed. São Paulo: Nacional, 1982.

JACOBI, P. Administração municipal, descentralização e participação. Educação Municipal, São Paulo, v. 3, n. 6, p. 7-19, jun. 1990.

KRAMNICK, I. Apresentação. In: MADISON, J. Os artigos federalistas. Rio de Janeiro: Nova Fronteira, 1993.

LEAL, V. N. Coronelismo, enxada e voto: o município e o regime representativo. São Paulo: Alfa-Omega, 1993.

MAIA, E. M. A descentralização do ensino no estado de São Paulo (1970-1987): democratização ou descompromisso? 1989. 309 f. Dissertação (Mestrado em Educação)- Faculdade de Educação, Universidade de São Paulo, São Paulo, 1989.

. A municipalização do ensino em processo: a experiência do Estado de São Paulo. ANDE, São Paulo, v. 9, n. 16, p. 10-16, 1990.

. Descentralização e democratização do ensino: dois estudos. Os estados de Minas Gerais e Rio Grande do Sul. 1995.

305 f. Tese (Doutorado em Educação)- Faculdade de Educação, Universidade de São Paulo, São Paulo, 1995.

MASCARO, C. C. 0 município de São Paulo e o ensino primário: ensaio de administração escolar. São Paulo: FAFIC; USP, 1960.

MELLO, G. N. de. É preciso dar um conteúdo concreto ao debate sobre a municipalização do ensino de 1.0 grau. Em aberto, Brasília, v. 5, n. 9, p. 19-24, jan./mar.1986.

. A municipalização e a questão do papel do Estado na sociedade brasileira. ANDE, São Paulo, v. 9, n. 16, p. 5-9, 1990.

NUNES, J. C. Do estado federado e sua organização municipal: história, doutrina, jurisprudência e direito comparado. Rio de Janeiro: Leite Ribeiro e Maurillo, 1920.

NUNES, 0. (Org.). 0 clamor dos municípios. In: CONGRESSO NACIONAL DE MUNICÍPIOS, 4., 1957, Rio de Janeiro. Anais... Rio de Janeiro: Ersol, 1957.

PAIM, A. Oliveira Vianna: vida e obra. In: VIANNA, O. Instituições políticas brasileiras. Belo Horizonte: Itatiaia, v. 2, 1987.

PERONI, V. Política educacional e papel do estado no Brasil dos anos 1990. São Paulo: Xamã, 2003.

PROUDHON, P.-J. Do princípio federativo. São Paulo: Imaginário; Nu-Sol, 2001.

ROMÃO, J. E. Administração municipal da educação. Educação Municipal, São Paulo, v. 3, n. 6, p. 37-52, jun. 1990.

Poder local e educação. São Paulo: Cortez, 1992.

ROSAR, M. de F. F. Globalização e descentralização: o processo de desconstrução do sistema educacional pela via da municipalização. 1995. 348 f. Tese (Doutorado em Educação)- Programa de Pós-Graduação em Educação, Universidade Estadual de Campinas, Campinas, 1995.

SALES, A. A pátria paulista. Brasília: EdUNB, 1983.

SANTOS, W. G. dos. Décadas de espanto e uma apologia democrática. Rio de Janeiro: Rocco, 1998.

SOUZA, C. Federalismo e descentralização na constituição de 1988: processo decisório, conflitos e alianças. Dados: Revista de Ciências Sociais, Rio de Janeiro, v. 44, n. 3, p. 513-560, 2001. 
TEIXEIRA, A. A educação e a crise brasileira. São Paulo: Nacional, 1956.

TIRAMONTI, G. Los imperativos de las políticas educativas de los 90. Revista da Faculdade de Educação, São Paulo, v. 23, n.1-

2, jan./dez. 1997. Disponível em: <http://www.scielo.com.br>. Acesso em: 20 ago. 2004.

TOCQUEVILLE, A. A democracia na América: leis e costumes. São Paulo: Martins Fontes, 2001. (Livro 1).

TORRES, A. A organização nacional - Primeira parte: a constituição. 4. ed. São Paulo: Nacional, 1982.

TORRES, J. C. de O. A formação do federalismo brasileiro. São Paulo: Nacional, 1967.

VIANNA, O. Evolução política do povo brasileiro. São Paulo: Nacional, 1938.

Instituições políticas brasileiras. São Paulo: EDUSP, v. 2, 1987.

Populações meridionais do Brasil: populações meridionais do centro-sul. In: SANTIAGO, S. (Coord.). Intérpretes do

Brasil. 2. ed. Rio de Janeiro: Nova Aguilar, v. 1, 2002. p. 919-1188.

XAVIER, R. Pela revitalização do município brasileiro. Rio de Janeiro: IBGE, 1948.

ZENHA, E. 0 município no Brasil: 1532-1700. São Paulo: Instituto Progresso, 1962.

Recebido em 14.04.09

Aprovado em 09.03.10

Gilda Cardoso de Araujo, bacharel em História e mestrado em Educação pela Universidade Federal do Espírito Santo (UFES), doutorado pela Faculdade de Educação da Universidade de São Paulo, é professora do Programa de Pós-Graduação da UFES na área de Política e Gestão Educacional. 